\title{
PERMASALAHAN DALAM DUNIA PENDIDIKAN YANG ADA DI INDONESIA
}

\author{
Rahmaniah \\ Email: 2010128320006@mhs.ulm.ac.id \\ Program Studi Pendidikan IPS Fakultas Keguruan dan Ilmu Pendidikan \\ Universitas Lambung Mangkurat \\ Banjarmasin
}

\begin{abstract}
Abstrak
Pendidikan merupakan suatu proses yang sangat penting untuk meningkatkan kecerdasan, keterampilan, mempertinggi budi pekerti, memperkuat kepribadian, dan mempertebal semangat kebersamaan agar dapat membangun diri sendiri dan bersama-sama membangun bangsa. Permasalahan pendidikan di Indonesia adalah segalam macam bentuk masalah yang dihadapi oleh program-program pendidikan di Indonesia. Adapun masalah yang rumit yang terdapat dalam dunia pendidikan formal seperti pemerataan pendidikan, mutu dan relevansi pendidikan, dan efisisensi pendidikan. Setiap masalah yang dihadapi ini disebabkan oleh faktor-faktor pendukungnya, adapun faktor-faktor yang menyebabkan berkembangnya masalah tersebut adalah IPTEK, permasalahan pembelajaran dan lajunya pertumbuhan penduduk.
\end{abstract}

\section{PENDAHULUAN}

Menururt Undang-Undang Sisdiknas Nomor 20 tahun 2003 pendidikan adalah usaha sadar dan terencana untuk mewujudkan suasana belajar dan proses pembelajaran agar peserta didik secara aktif dapat mengembangkan potensi dirinya untuk memiliki kekuatan spritual keagamaan, pengendalian diri, kepribadian, kecerdasan, akhlak mulia serta keterampilan yang diperlukan dirinya, masyarakat, bangsa dan negara. Adapun pengertian pendidikan menurut Saptono (2017), pendidikan merupakan suatu proses yang sangat penting untuk meningkatkan kecerdasan, keterampilan, mempertinggi budi pekerti, 
memperkuat kepribadian, dan mempertebal semangat kebersamaan agar dapat membangun diri sendiri dan bersama-sama membangun bangsa.

Pendidikan dibagi menjadi 3 (tiga), yaitu pendidikan formal, pendidikan informal, dan pendidikan non-formal. Pendidikan formal terdiri dari SD hingga ke perguruan tinggi. Pendidikan informal merupakan jenis pendidikan atau pelatihan yang terdapat di dalam keluarga atau masyarkat dan diselenggarakan tanpa ada organisasi tertentu. Sedangkan pendidikan non-formal memiliki arti yaitu segala bentuk pendidikan yang diberikan secara terorganisasi tetapi diluar wadah pendidikan formal. Dan pada kali ini akan dibahas mengenai permasalahan yang berkaitan dengan pendidikan formal.

Pada dasarnya setiap kegiatan memiliki dampak positif dan dampak negatif. Begitu juga dalam dunia pendidikan. Penerapan pendidikan yang berjalan secara tidak baik maka akan menimbulkan dampak negatif. Hal ini merupakan penghambat bagi proses kelancaran dalam belajar mengajar. Dan peristiwa ini pun banyak terjadi dalam dunia pendidikan formal.

Permasalahan pendidikan di Indonesia adalah segalam macam bentuk masalah yang dihadapi oleh program-program pendidikan di Indonesia. Adapun masalah yang rumit yang terdapat dalam dunia pendidikan formal seperti pemerataan pendidikan, mutu dan relevansi pendidikan, dan efisisensi pendidikan. Setiap masalah yang dihadapi ini disebabkan oleh faktor-faktor pendukungnya, adapun faktor-faktor yang menyebabkan berkembangnya masalah tersebut adalah IPTEK, permasalahan pembelajaran dan lajunya pertumbuhan penduduk.

\section{PERMASLAHAN PENDIDIKAN DI INDONESIA}

Permasalahan pendidikan merupkan suatu penghambat keberhasilan dalam mencapai tujuan pendidikan. Berikut akan dijelaskan mengenai beberapa masalah pendidikan yang dihadapi oleh bangsa Indonesia.

\section{A. Pemerataan Pendidikan}

Permasalahan pemertaan pendidikan dapat terjadi karena kurangnya terorganisir koordinasi antara pemerintah pusat dan pemerintah daerah, bahkan hingga daerah terpencil sekalipun. Maka hal ini dapat menyebabkan terputusnya komunikasi antara pemerintah 
pusat dengan pemerintah daerah. Permasalahn pendidikan juga dapat terjadi karena kurang berdayanya lembaga pendidikan untuk melakukan proses pendidikan. Hal ini bisa terjadi apabila kontrol pendidikan yang dilakukan oleh pemerintah pusat dan pemerintah daerah tidak dapat menjangkau daerah-daerah terpencil. Jadi hal ini dapat berakibat pada mayoritas penduduk Indonesia dalam usia sekolah yang tidak dapat mengenyam pendidikan sebagaimana yang diharapkan.

Selama ini dapat dipahami bahwa belum semua masyarakat bangsa Indonesia dapat mengenyam atau dapat merasakan manisnya pendidikan. Persoalan pemerataan pendidikan di Indonesia berdasarkan pendapat Idrus (2016) diantaranya disebabkan oleh:

1) Perbedaan tingkat sosial,

2) Perbedaan fasilitas pendidikan,

3) Sebaran sekolah tidak merata,

4) Nilai masuk sebuah sekolah dengan standart yang tinggi,

5) Rayonisasi (pengelompokkan pada sistem penerimaan siswa baru di sekolah).

Yang paling utama permasalahan pendidikan di Indonesia adalah tingkat ekonomi. Semakin rendah tingkat ekonomi masyarakat, maka untuk endapatkan pendidikan yang tenaga pengajarnya berkualitas semakin kecil. Fasilitas dalam pendidikan pun juga diukur dengan uang. Semakan mahal biaya sekolah, maka biasanya semakin memadai juga fasilitas yang ada.

Permasalahan pemerataan pendidikan ini dapat ditanggulangi dengan menyediakan fasilitas dan sarana belajar bagi setiap lapisan masyarakat yang wajib mendapatkan pendidikan. Pemberian sarana dan prasrana pendidikan pun sebaiknya dilakukan oleh pemerintah dengan setransparan mungkin, sehingga tidak ada lagi oknum yang dapat mempermainkan program yang dijalankan ini.

B. Mutu dan Relevansi Pendidikan

Rendahnya kualitas tenaga pengajar menyebabkan rendahnya mutu dan relevansi pendidikan. Penilaian tersebut dapat dilihat dari kualisifikasi belajar yang dapat dicapai oleh guru dan dosen. Dibandingkan dengan negara berkembang lainnya, maka kualitas tenaga pengajar pendidikan tinggi di Indonesia memiliki masalah yang sangat mendasar. 
Itulah sebabnya seorang tenaga pengajar harus bisa engedepankan kreativitas agar mendapatkan mutu yang baik dan mempunya pengaruh positif terhadap rangkaian pembelajaran, hal ini juga dapat mempengaruhi kecepatan daya tangkap suatu imu yang dicerna oleh peserta didik selama proses pembelajaran berlangsung.

C. Efisiensi dan Efektifitas Pendidikan

Pelakasanaan pendidikan yang efisien dalah apabila penggunaan sumber daya seperti waktu, tenaga, dan biaya tepat sasaran, dengan lulusan dan produktifitas pendidikan yang optimal. Pada saat ini pelakasanaa pendidikan di Indonesia jauh dari kata efisien, karena dalam pemanfaatan sumber daya yang ada tidak menghasilkan lulusan yang diharapkan. Pendidikan yang diperoleh tidak menjamin seseorang untuk mendapatkan pekerjaan yang sesuai dengan jenjang pendidikan yang dijalani.

Adapun pendidikan yang efektif adalah pelaksanaan pendidikan dimana hasil yang dicapai sesuai dengan rencana yang telah ditetapkan sebelumnya. Ketidakefektifan pelaksanaan dalam pendidikan tidak akan mampu menghasilkan lulusan yang berkualitas. Melainkan akan menghasilkan lulusan yang tidak diharapkan. Keadaan ini akan menghasilkan masalah lain seperti pengangguran.

\section{FAKTOR PENDUKUNG DARI PERMASALAHN PENDIDIKAN DI INDONESIA}

Terdapat beberapa faktor pendukung dari permasalahan pendidikan yang ada di Indonesia, yaitu:

\section{A. IPTEK}

Karena adanya penemuan teknologi baru dalam dunia pendidikan, maka menuntut Indonesia untuk melakukan reformasi dalam bidang pendidikan. Tidaklah mudah dalam melaksanakan reformasi, karena hal ini sangat menuntut kesiapan Sumber Daya Manusia Indonesia untuk menjalankannya.

B. Permasalahan Pembelajaran

Pada masa sekarang ini, aktivitas proses pembelajaran yang dilaksanakan cenderung lebih pasif, dimana seorang pendidik selalu menempatkan dirinya sebagai orang yang serba tahu. Hal ini akan menimbulkan rasa bosan terhadap peserta didik. Dengan demikian, pembelajaran yang dilaksanakan menjadi tidak menarik dan cenderung membosankan. 
Kegiatan belajar yang dilaksanakan seperti ini merupakan suatu masalah yang begitu serius pada dunia pendidikan.

C. Lajunya Pertumbuhan Penduduk

Lajunya pertumbuhan penduduk yang sangat pesat akan berpengaruh tehadap masalah pemerataan serta mutu dan relevansi pendidikan. Pertumbuhan penduduk akan berdampak pada jumlah peserta didik. Semakin besar jumlah pertumbuhan penduduk, maka semakin banyak pula dibutuhkan sekolah-sekolah untuk menampungnya. Jika daya tampung suatu sekolah tidak memadai, maka akan banyak peserta didik yang terlantar atau tidak bersekolah. Hal ini akan menimbulkan masalah pemerataan dalam dunia pendidikan. Tetapi apabila jumlah dan daya tampung suatu sekolah itu dipaksakan, maka hal tersebut akan berakibat terjadinya ketidakseimbangan antara tenaga pengajar dengan peserta didik. Jika keadaan ini dipertahankan, maka mutu dan relevansi pendidikan tidak akan dapat dicapai dengan baik.

\section{SIMPULAN}

Dalam usaha pemerataan pendidikan maka diperlukan pengawasan yang serius oleh pemerintah. Selain itu, perluasan kesempatan belajar pada jenjang pendidikan tinggi merupakan kebijaksanaan yang penting dalam usaha pemerataan pendidikan. Pendidikan dalam usaha pengendalian lajunya pertumbuhan penduduk sangat diperlukan. Pelaksaaan program ini dapat ditingkatkan dengan mengakampanyekan program KB dengan sebaikbaiknya hingga pelosok negeri ini. Pelaksanaan program belajar dan mengajar dengan inovasi baru perlu diterapkan. Hal ini dilakukan karena cara dan sistem pengajaran lama tidak dapat diterapkan lagi. Peningkatan mutu pendidikan akan dapat terlaksana jika kemampuan dan profesionalisme pendidik dapat ditingkatkan.

\section{REFERENSI}

Abbas, E. W. (2013). Mewacanakan Pendidikan IPS. Mewacanakan Pendidikan IPS.

Abbas, E. W. (2015). Pendidikan IPS Berbasis Kearifan Lokal. WAHANA Jaya Abadi. 
Abbas, E. W. (2018). Penguatan Pendidikan IPS Di Tengah Isu-Isu Global.

Indriyani, I. E., Syaharuddin, S., \& Jumriani, J. (2021). Social Interaction Contents on Social Studies Learning to Improve Social Skills. The Innovation of Social Studies Journal, 2(2), 93-102.

Mujahidun. (2017). PEMERATAAN PENDIDIKAN ANAK BANGSA: PENDIDIKAN GRATIS VERSUS KAPITALISME PENDIDIKAN Mujahidun. Tarbiyatuna, 8(1), $1-8$.

Mutiani, M., Noortyani, R., Tetep, T., Jumriani, J., \& Widyanti, T. (2020). Strengthening Islamic Environmental Awareness through Exploring Poetry as a Learning Resource in Social Studies. Islam Realitas: Journal of Islamic and Social Studies, 6(2), 153166.

Mutiani, M., Supriatna, N., Abbas, E. W., Rini, T. P. W., \& Subiyakto, B. (2021). Technological, Pedagogical, Content Knowledge (TPACK): A Discursions in Learning Innovation on Social Studies. The Innovation of Social Studies Journal, 2(2), 135-142.

Putra, M. A. H., Mutiani, M., Jumriani, J., Ramadhan, S., \& Rahmatina, R. (2020). Utilization Learning Management System (LMS) of Ruang Guru for Education Teachers in Banjarmasin. The Kalimantan Social Studies Journal, 2(1), 31-38.

Putro, H. P. N., \& Jumriani, J. (2020). KEHIDUPAN SOSIAL DAN EKONOMI MASYARAKAT BANTARAN SUNGAI A SEBAGAI SUMBER BELAJAR IPS.

Priscilla, D. (2019). Permasalahan Pendidikan di Indonesia.

Saptono, A. (2017). Pengaruh Kreativitas Guru Dalam Pembelajaran Dan Kecerdasan Emosional Siswa Terhadap Prestasi Belajar Ekonomi Pada Siswa Kelas X Di Sma Negeri 89 Jakarta. Econosains Jurnal Online Ekonomi Dan Pendidikan, 14(1), 105112. https://doi.org/10.21009/econosains.0141.08 